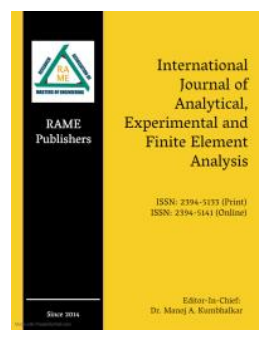

Roshan Babar ${ }^{1}$ babarroshan2@gmail.com

Abhay kale ${ }^{1}$ abhay09kale@gmail.com

Shahid Bagwan ${ }^{1}$ bagwanshahid155@gmail.com

Onkar Sonawnane ${ }^{1}$ onkarsonawane019@gmail.com

A. N. Shaikh ${ }^{2}$ alimoddinnshaikh@gmail.com

${ }^{1}$ Assistant Professor and ${ }^{2}$ Student Department of Mechanical Engineering, JSPM Narhe technical Campus, Narhe, Pune, India

\section{Design \\ and Automatic Pipe Cutting Machine \\ Analysis Feeding and}

Abstract - The main objective of this paper is to design \& analysis of an automatic operated pipe cutting machine. Engineers are developing refined machines and modern techniques are employed for economical manufacturing of products. At the same time, we should care about its quality and accuracy. In the era of automation, machines become an intrinsic part of human being. By the use of automation, machine gives great production rate than manual manufacturing process. In today's competitive market automation has powerfully entered in the industrial manufacturing process in order to increase the production rate and to reduce the process time without conceding with the accuracy of the product. Automatic pipe cutting machine is designed for industries to fragments metals pipes, rods or cylinders of accurate dimensions with high accuracy in less time. oil is used as a working fluid which is pumped with high pressure through pump to perform the mechanical work with the use of proper mechanism. Operator can easily operate Automatic pipe cutting machine. The running and maintenance rate of this machine is very cost-effective.

Keywords - Automatic pipe cutting, FE Analysis, Arduino programming.

\section{INTRODUCTION}

Now a days industries are focusing on making the machines automatic as large number of identical components are produced in mass production which further increases the manufacturing cost of product. Automation in the machining process reduces the cost of production as well as human involvement [1]. Cutting operation is commonly used in most of the manufacturing process practiced in industries and cutting by conventional method is not accurate and also time consuming. This paper focuses on the automation of the pipe cutting machine. Accurate cutting of pipe with exact dimensions is ensured

Research Paper - Peer Reviewed

Published online - 30 June 2021

(C) 2021 RAME Publishers

This is an open access article under the CC BY 4.0 International License https://creativecommons.org/licenses/by/4.0/

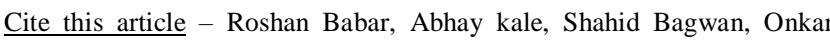
Sonawnane, A. N. Shaikh, "Design and Analysis of Automatic Pipe Feeding and Cutting Machine", International Journal of Analytical, Experimental and Finite Element Analysis, RAME Publishers, vol. 8, issue 2, pp. 58-62, 2021.

https://doi.org/10.26706/ijaefea.2.8.20210710 in Automatic pipe cutting machine [2]. Therefore, we have designed an automatic machine which can be used in industries for pipe cutting operation in order to increase the production and to reduce the process time without compromising with the accuracy of the product. Oil is used as a working fluid; pressurized oil is pumped through pump which can be used to perform the mechanical work with the use of proper mechanism [3]. The mechanism is made fully automatic with help of Arduino programming. The construction of the machine robust and a semi-skilled operator can easily work on this machine and the running as well as maintenance cost of this machine is machine is low $[4,5]$.

\section{A. Objectives}

- The objective of this project is to cut the pipe in less time and with minimal burr produced around the pipe.

- Design and develop a model which reduce human interference with machine.

- To provide automatic feeding mechanism controlled by Arduino programming 
- To create a product which is use for mass production $\&$ make it cost effective and easy to use.

\section{B. Methodology}

First to create base of the frame on which all things will be mounted.

- Then we design vertical frame on which our grinding wheel will be mounted.

- Then to move our grinder wheel up and down we will use hydraulic system, which will be mounted above our wheel

- Then we will mount rollers on base of the frame for forward and backward movement of pipe.

- Then we fix the motor under the roller to move the pipe.

- Then we will use pump to supply oil to our hydraulic system.

- After all this we do Arduino programming \& give all the necessary connections

- Then after this we will do Structural Analysis of grinder wheel and pipe.

\section{DESCRIPTION OF COMPONENTS}

The components used for the design and manufacturing of machine with their detail description are as follows [6-9].

\section{A. Grinder}

These wheels are formed from an abrasive disc that is usually solid in nature. As a result of a combination of gravel and bonding agent, they are shaped into a thin, hard disc with fibre nets running through it for added strength.

\section{B. Hydraulic}

A hydraulic system allows pressure applied to a fluid at any point in the system to be transmitted without loss. Every portion of the unit of a contained vessel is affected by this pressured fluid, which generates force or power.

\section{Pump}

An electric motor is used to transform electrical energy into hydraulic energy, which is then used to move fluids (liquids or gases), or occasionally slurries. They are powered by a mechanism (typically reciprocating or rotating) and need energy to move fluid.

\section{Stepper Motor}

Also known as a stepper motor or a stepping motor, the brushless DC electric motor completes a full rotation in a series of discrete steps.

\section{E. Arduino}

An open-source electronics platform built on hardware and software that's easy to use, Arduino is available for free. Recited inputs are supported by Arduino boards.

\section{CAD MODEL AND WORKING}

First the pipe is mounted on rollers and supply power to steeper motor. Once steeper motor start rotating, it will feed the pipe in the horizontal direction. After required distance the current to the steeper motor will disconnect and it will supply power to pump. Then pump will supply pressurized liquid to hydraulic system, With the help of hydraulic system our grinder/cutter will move in vertically downward direction and will cut the pipe. After pipe has been cut, the fluid from hydraulic system will flow out through exit valve to the reservoir and grinder/cutter will move to its original place. This all process will be controlled with the help of Arduino coding.

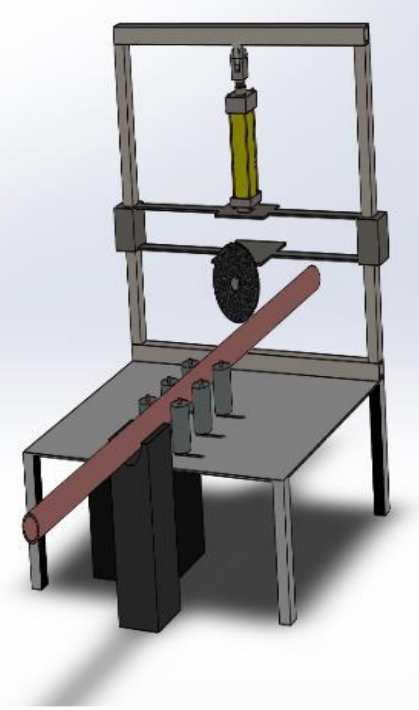

Figure 1. CAD model 


\section{Finite Element Analysis}

A finite element analysis is a method based on CAD model with boundary conditions to get accurate results by providing proper selection of material and their definite properties with types of elements. An imported model in ANSYS is meshed with tetrahedral SOLID 187 element as shown in figure 3 . For the boundary condition, $100 \mathrm{~N}$ force is applied tangentially over the roller and fixed at the end of pipe. Also, displacement is given to roller to allow its rotation as shown in figure 4 . The results have been evaluated for the different thickness of roller such as 0.5 $\mathrm{mm}, 1 \mathrm{~mm}$ and $1.5 \mathrm{~mm}$. An equivalent stresses and deformations of roller with pipe for different thicknesses are shown from figure 5 to figure 10 and the results obtained are shown in table 1 and figure 11 and figure 12.

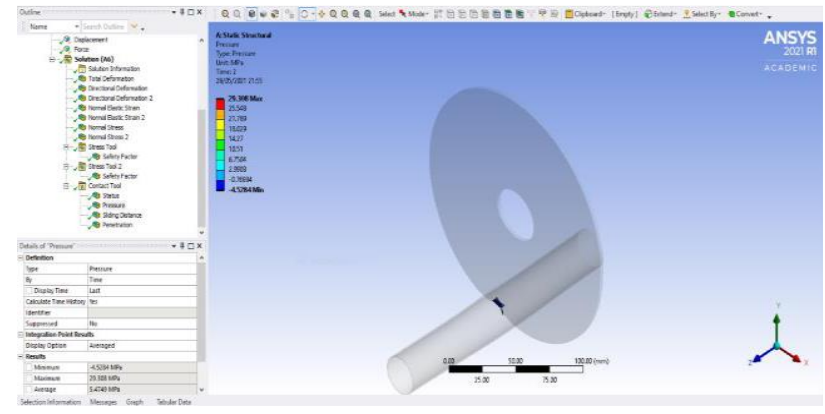

Figure 2: Contact and target region

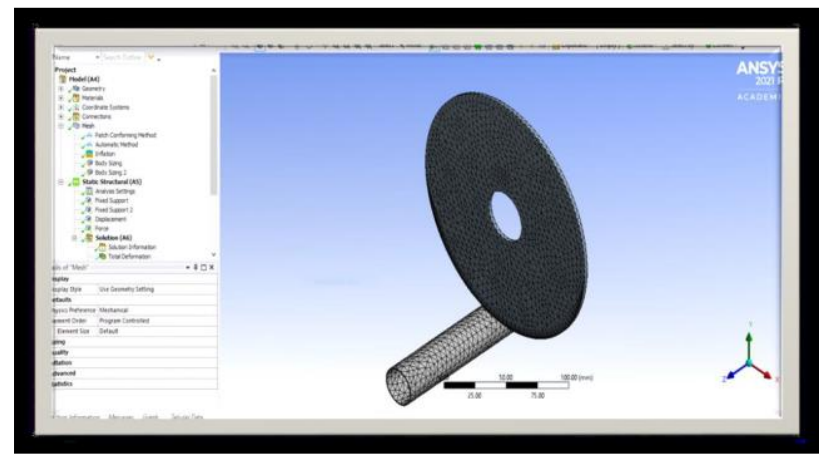

Figure 3: Meshing

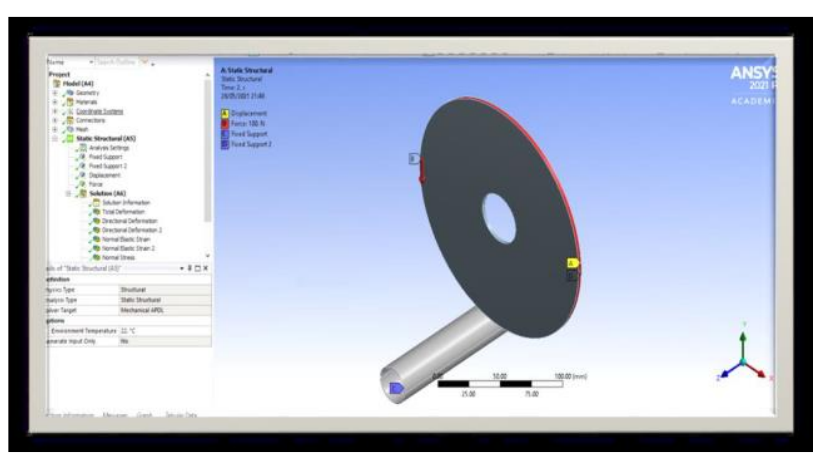

Figure 4: Boundary Condition
A. FE Analysis Result for $0.5 \mathrm{~mm}$ Thickness of wheel

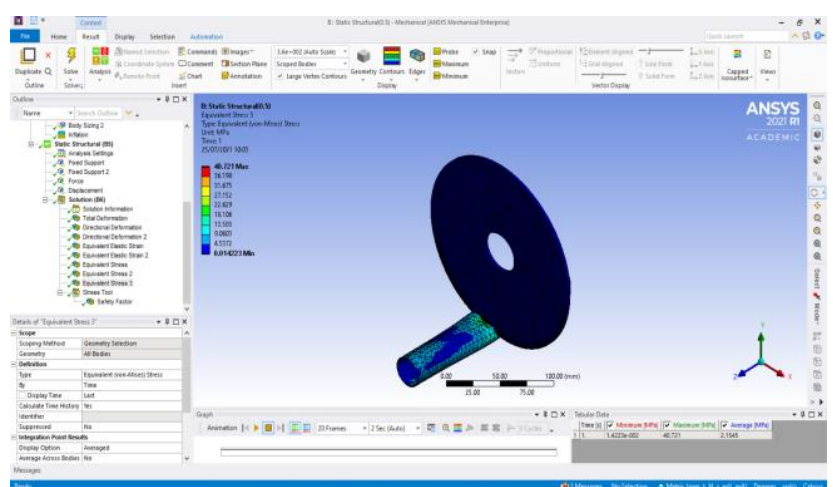

Figure 5: Equivalent stress of $40.721 \mathrm{MPa}$ for $0.5 \mathrm{~mm}$ thickness of wheel

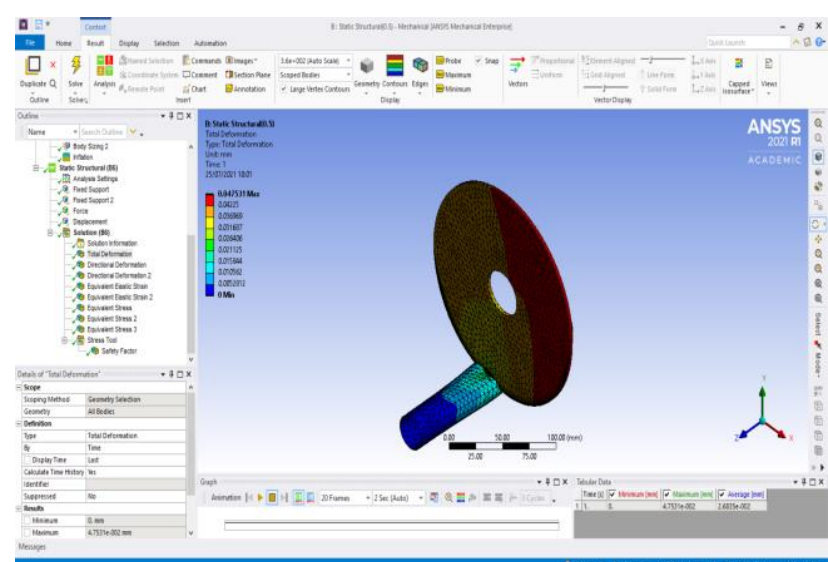

Figure 6: Deformation of $0.0473 \mathrm{~mm}$ for $0.5 \mathrm{~mm}$ thickness of wheel

\section{B. FE Analysis Result for $1 \mathrm{~mm}$ Thickness of wheel}

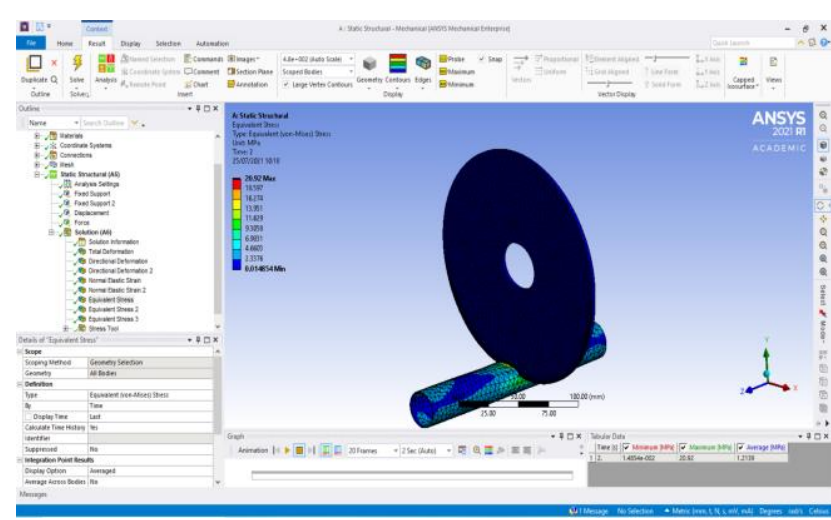

Figure 7: Equivalent stress of $20.92 \mathrm{MPa}$ for $1 \mathrm{~mm}$ thickness of wheel

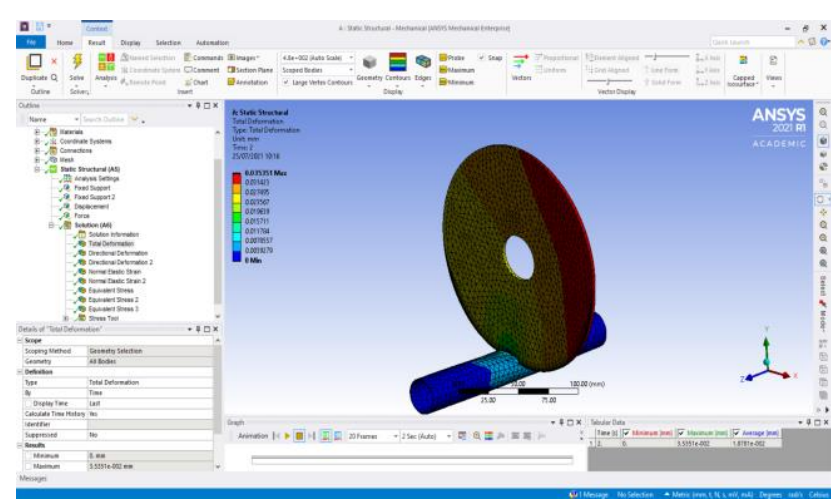

Figure 8: Deformation of $0.0353 \mathrm{~mm}$ for $1 \mathrm{~mm}$ thickness of wheel 


\section{FE Analysis Result for $0.5 \mathrm{~mm}$ Thickness of wheel}

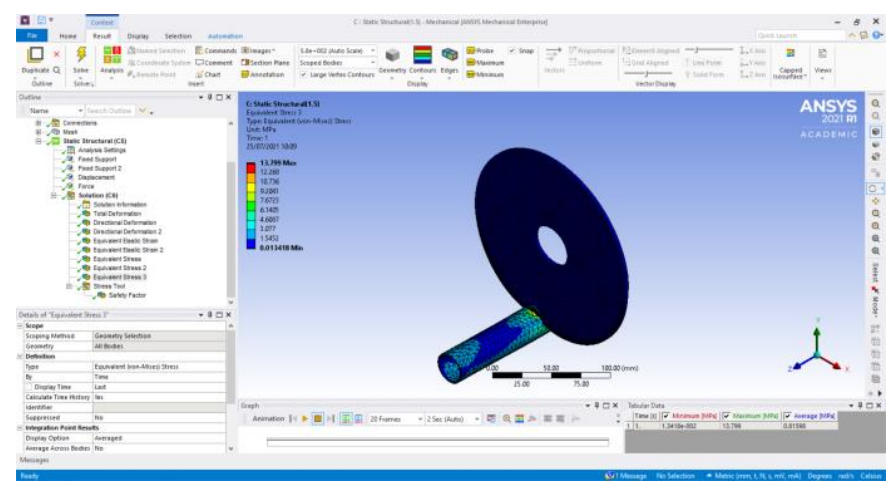

Figure 9: Equivalent stress of 13.79 MPa for $1.5 \mathrm{~mm}$ thickness of wheel

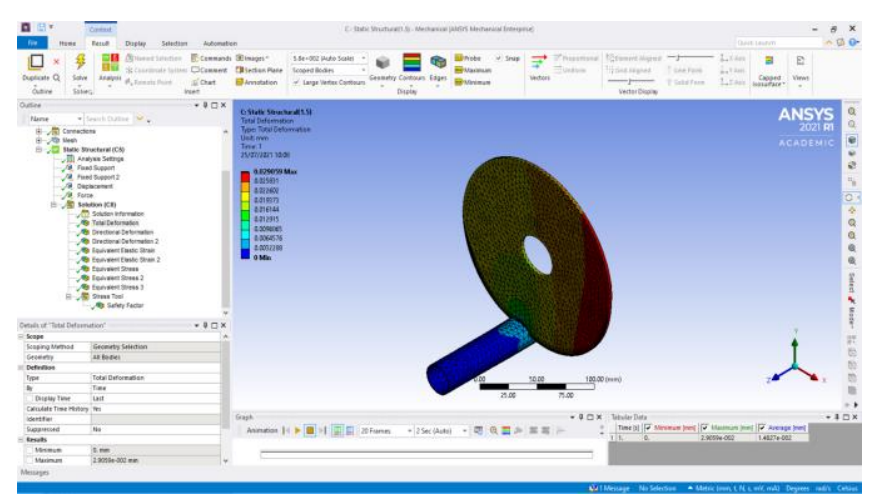

Figure 10: Deformation of $0.029 \mathrm{~mm}$ for $1.5 \mathrm{~mm}$ thickness of wheel

TABLE I

FE ANALYSIS RESULT FOR DIFFERENT THICKNESS OF WHEEL

\begin{tabular}{|c|c|c|}
\hline $\begin{array}{c}\text { Thickness } \\
(\mathrm{mm})\end{array}$ & $\begin{array}{c}\text { Maximum } \\
\text { Stress (MPA) }\end{array}$ & $\begin{array}{c}\text { Total } \\
\text { Deformation(mm) }\end{array}$ \\
\hline $0.5 \mathrm{~mm}$ & 40.721 & 0.0473 \\
\hline $1 \mathrm{~mm}$ & 20.92 & 0.0353 \\
\hline $1.5 \mathrm{~mm}$ & 13.79 & 0.0290 \\
\hline
\end{tabular}

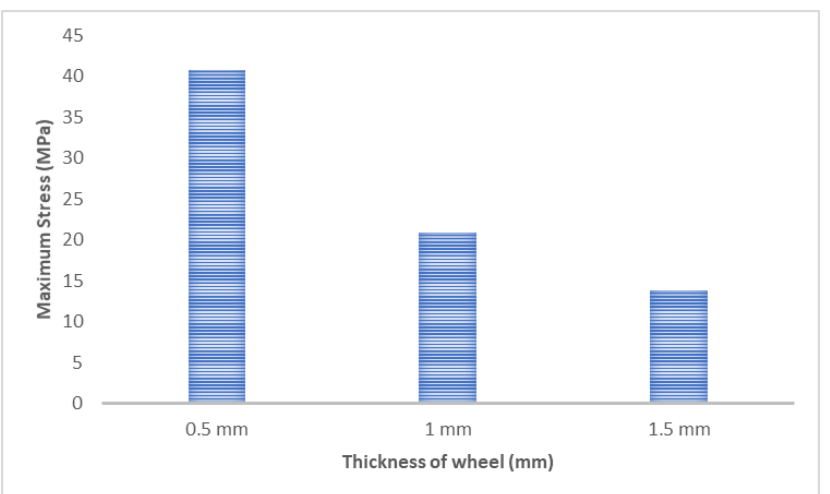

Figure 11: Maximum stress on wheel with respect to its thickness

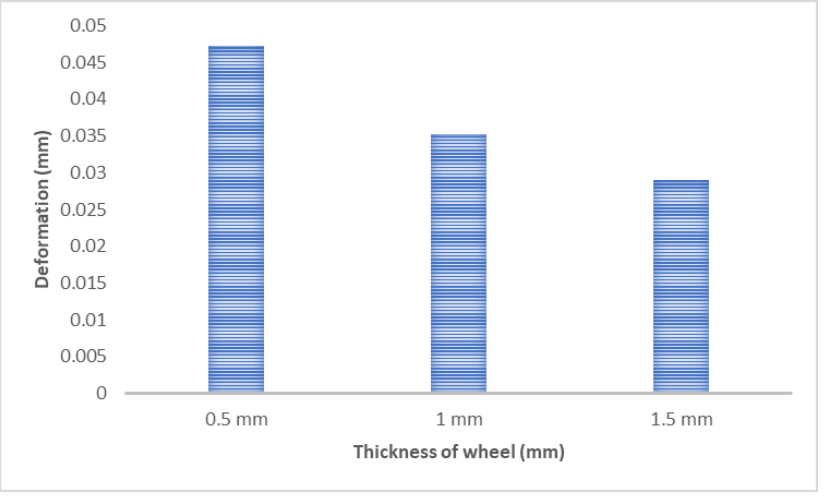

Figure 12: Deformation of wheel with respect to its thickness

\section{CONCLUSION}

This machine provides an alternative to the existing pipe cutting machine, in the terms of-

- By using Automatic feeding mechanism to move pipe in and out from the cutting apparatus.

- Time consumption is very less as compared to manual cutting.

- Initial investment is very less.

\section{REFERENCES}

[1] Mikell P. Groover, Yoram Korean, “Automation Production System, and Computer-Integrated Manufacturing”, Pearson Publication, 9th edition, 1983.

[2] Prof. P.D. Menghani, Akarsh Jaiswal, Nikhil Jain, Mansi Borse, "Automatic Pipe Cutting Machine", International Conference on Ideas, Impact and Innovation in Mechanical Engineering, Volume: 5 Issue: 6, 2017, pp. 641 -643.

[3] Shital K.Sharma, Ashish V. Waghmare, Pranit S. Wakhare, Automatic bar feeding mechanism for pipe cutting machine, $5^{\text {th }}$ International Conference on Recent Trends in Engineering, Science and Management, December 2016.

[4] Marco Manzonea, Sara Berganteb, Gianni Facciottob, Paolo Balsaria, "A prototype for horizontal long cuttings planting in Short Rotation Coppice", Biomass \& Bioenergy, Volume 107, 2017, pp. 214-218.

[5] Ajit Kumar Singh \& Harpreet Singh, "Design and Fabrication of Pneumatic Auto Sheet Metal Cutting Machine Using Solar Energy", International Journal of Engineering Research \& Technology (IJERT), Volume 4, 2015, pp. 654657.

[6] A. S. Aditya Polapragada \& K. Sri Varsha, "Pneumatic Auto Feed Punching and Riveting Machine", International 
Journal of Engineering Research \& Technology (IJERT), volume 7, 2012, pp. 2278- 0181.

[7] N. Shripad, V. Sagar, P. Abhay, V. Pooja, "Pneumatically Operated Automatic Pipe-Cutting Machine", International Journal of Advance Research and Innovative Ideas in Education, 2, 2016, 1767- 1772.

[8] Sathishkumar, K., Ugesh, N., Vignesh, K., \& Prasath, P., "Pneumatic Reciprocating Hacksaw Machine", International
Conference on Breakthrough in Engineering, Science \& Technology, volume 3, 2016, pp. 6-10.

[9] Nagpure, K., Charkhod, R., Aher, V., \& Chauhan, S., “Automatic Pneumatic Pipe Cutting Machine”, International Journal of Advance Research and Innovative Ideas in Education, 3, 2017, 1542-1544. 